\title{
Hình dung được dụ án mạo hiểm nhưng chưa hình dung về doanh thu
}

\author{
Thánh Gióng Portal
}

November 6, 2013

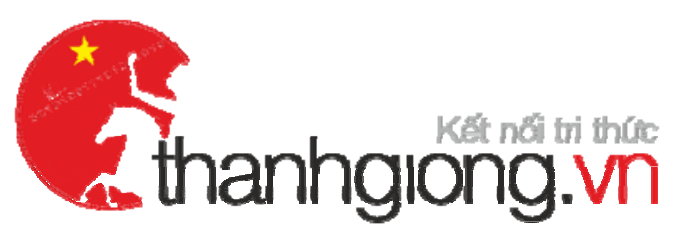

Trung ương Hội Liên hiệp Thanh niên Việt Nam

https://thanhgiong.vn/hinh-dung-duoc-du-an-mao-hiem-nhung-chuahinh-dung-ve-doanh-thu-17150.html 


\title{
Hình dung được dự án mạo hiểm nhưng chưa hình dung về doanh thu
}

\author{
(CTG) Đó là tình trạng chung của 3 đội có ý tưởng khởi \\ nghiệp xuất sắc khu vực miền Trung trong cuộc thi Sáng tạo \\ tương lai của Hành trình vì Khát vọng Việt 2013.
}

Đội đến từ trường Đại học Bách khoa Đà Nẵng đã xuất sắc đoạt giải nhất khu vực và đại diện miền Trung bước tiếp vào vòng bán kết và chung kết của cuộc thi toàn quốc tại TPHCM (21 và 22/11). Đây là đội đầu tiên trong suốt cuộc thi STTL đã hình dung dự án của mình là một dự án mạo hiểm mà chưa có hình dung về doanh thu. Ngoài khát vọng và động lực thì để có ý tưởng đôi khi cũng đòi hỏi sự mơ mộng, nhưng khi lên kế hoạch triển khai lại đòi hỏi sự thực dụng. Vì thể các bạn sinh viên cũng nên nhớ rằng trong một người cần có nhiều con người, ngoài Sáng tạo cũng cần có tinh thần Doanh nhân và tinh thần Chiến binh như anh Đặng Lê Nguyên Vũ thường nói: “Tinh thần doanh nhân - chiến binh - sáng tạo cần được nhanh chóng khởi phát mạnh mẽ ngay chính trong cộng đồng Việt bằng nhiều phương tiện liên hoàn để chúng ta có nền tảng mềm, nhưng vô cùng quan trọng trong tiến trình phục hưng kinh tế, đưa đất nước vào vị thế quốc gia thịnh vượng bền vững, xây dựng một thế hệ doanh nhân mới với hoài bão (chinh phục và ảnh hưởng) và 3 tinh thần (chiến binh, doanh nhân và sáng tạo)". Doanh nhân đích thực là phải biết làm giàu bền vững, không chỉ làm giàu cho bản thân mà còn làm giàu cho gia đình, đất nước, phải dám đương đầu với thách thức, biết cân nhắc và tính toán thật kỹ trong từng bước đi, hạn chế tâm lý thử sai ở đa số thanh niên hiện nay. "Chúng ta có thể chấp nhận rủi ro nhưng là rủi ro sau khi đã tính toán kỹ lưỡng nhất, không phải mạo hiểm khi chưa tính toán gì, đó là một điều cực kỳ nguy hiểm mà tôi đặc biệt cảnh tỉnh ở các bạn trẻ”, TS Phan Tát Thứ chia sẻ với các bạn sinh viên Đà Nẵng tại diễn đàn giao lưu "Sáng tạo vì Khát vọng Việt" đêm qua 6/11/2013 với chủ đề "Người khác làm được thì ta làm được". 


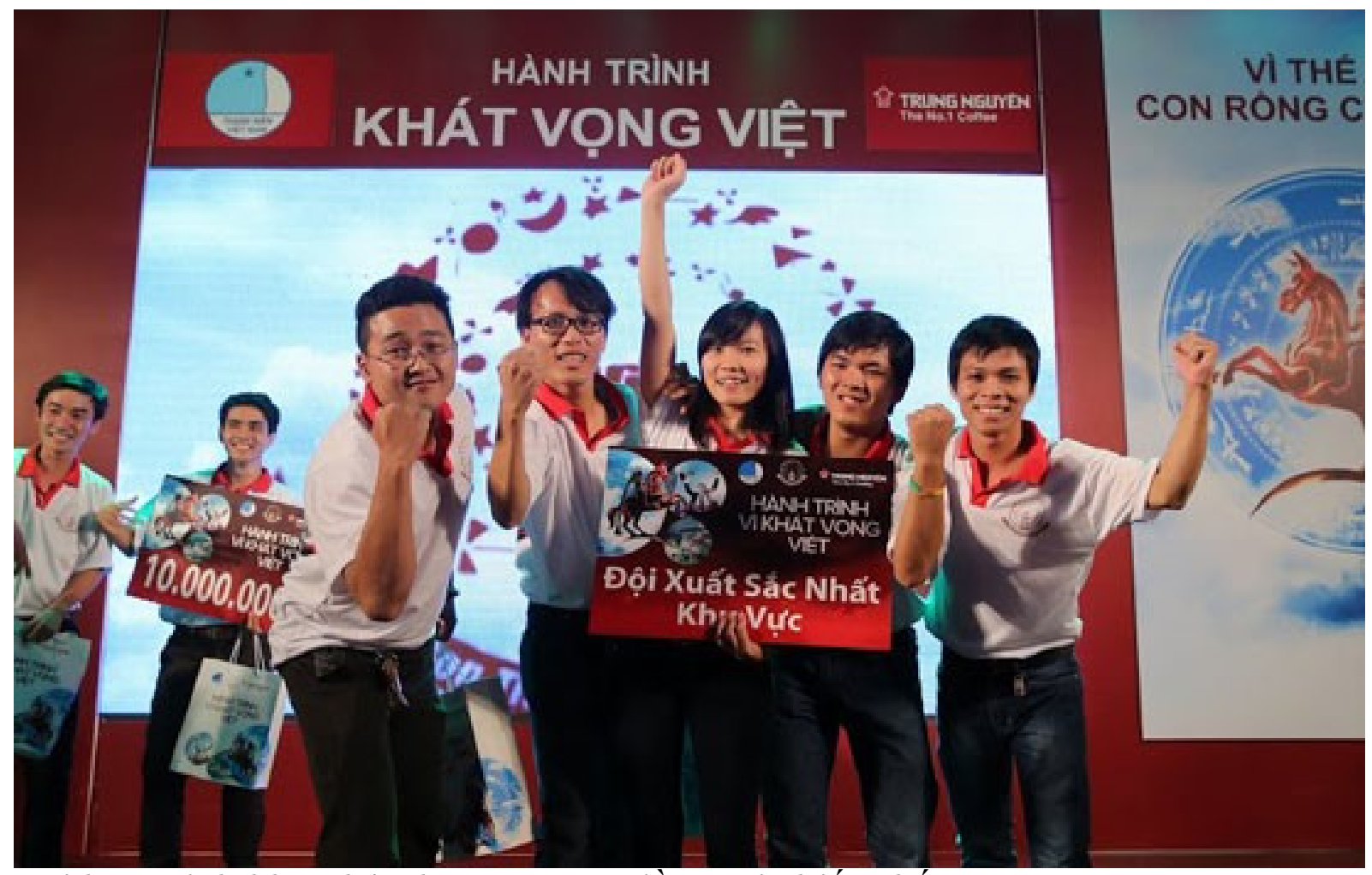

Đại học Bách khoa hân hoan trong niềm vui chiến thắng.

Tuy nhiên, điểm đặc biệt ở các bạn trường Đại học Bách Khoa Đà Nẵng là các bạn vẫn nhận thức được dự án "Xây dựng và kinh doanh phần mềm hướng dẫn viên du lịch điện tử - ITourGuide" của mình là dự án mạo hiểm nhưng vì đam mê, động lực, khát vọng và niềm tin mạnh mẽ rằng dự án này sẽ đóng góp vào sự phát triển và quảng bá cho thành phố Đà Nẵng quê hương mình nên dù đầu tư mạo hiểm các bạn vẫn sẵn sáng làm và theo đuổi. Niềm tin này cũng được cả 3 vị giám khảo của chương trình đồng ý và khích lệ: "Với dự án này, các bạn nên kêu gọi đầu tư từ nhà nước sẽ có hướng phát triển lạc quan, có thể gửi cho Bộ Văn hóa thông tin để kêu gọi đầu tư. Cơ hội của các bạn không chỉ gói gọn trong một vài sự quan tâm mà có thể mở rộng hơn nữa, vậy nên hãy biết nắm bắt", giám khảo Nguyễn Tuấn Quỳnh chia sẻ.

Nổi tiếng là vị giám khảo khó tính nhất trong cuộc thi STTL từ đầu chương trình đển nay, sự khích lệ của anh đặc biệt có ý nghĩa với đội Đại học Bách Khoa Đà Nẵng: "Bọn em rất vui khi nhận được những góp ý quý báu và sự khích lệ từ ban giám khảo, đặc biệt là anh Tuấn Quỳnh, giúp chúng em tự tin hơn rất nhiều", thành viên của đội Đại học Bách khoa Đà Nẵng chia sẻ.

Trái với đội Đại học Bách khoa Đà Nẵng, đội Đại học Kinh tế Đà Nẵng đã có một kế hoạch triển khai cho ý tưởng dự án "Hệ thống cho thuê xe linh hoạt đầu tiên tại Việt Nam" cực kỳ chi tiết về mặt con số. Đội có số điểm sát sao và chỉ kém đội Đại học Bách khoa Đà Nẵng 1 điểm duy nhất và cũng là đội khiến ban giám khảo phải tranh luận rất nhiều trước khi đưa ra quyết định mặc dù cũng là đội bị ban giám khảo chất 
vấn nhiều nhất.

"Dự án của các bạn như một bài toán tính xuôi chưa thực tế, chưa tính hết các chi phí phát sinh, chưa lường hết những rủi ro có thể xảy ra", TS. Vương Quân Hoàngnghiêm khắc góp ý.

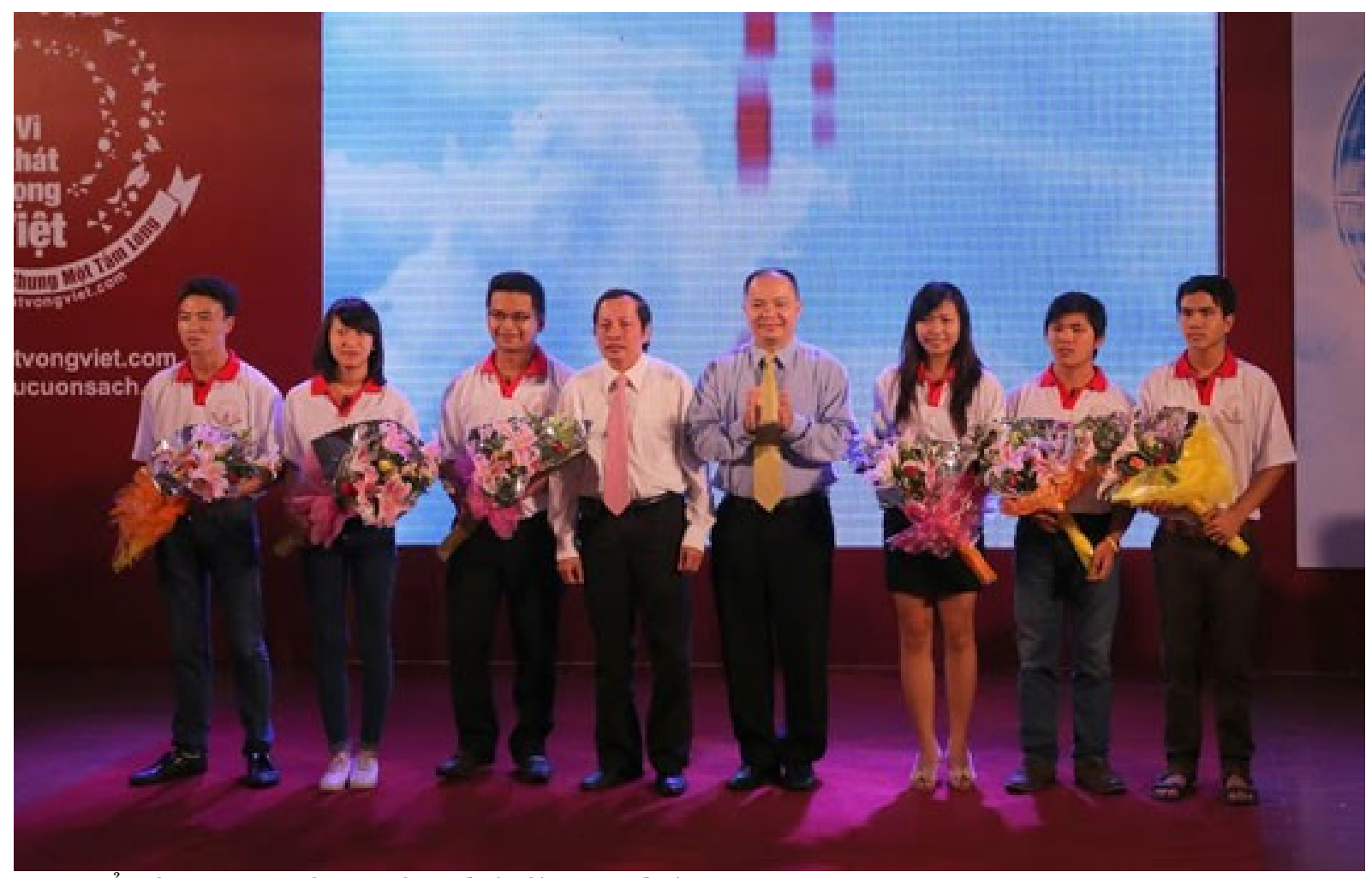

Ban tổ chức tặng hoa cho đại diện 6 đội.

Tính thực tế, các tình huống rủi ro có thể và đã từng xảy ra khi lưu thông trên đường phố cũng đã được Giám khảo Nguyễn Tuấn Quỳnh đặt ra liên tiếp cho các bạn đội Đại học Kinh tế Đà Nẵng. Từ việc nhận - trả giấy tờ tuỳ thân khi khách thuê và trả xe giữa các điểm khá xa nhau, yêu cầu phải có bằng lái xe máy trên đường phố $\mathrm{VN}$ mà thông thường người nước ngoài ít khi có, cho đến những rủi ro về mất xe, bị thu xe, khách gây tai nạn,...Anh Quỳnh bỗng dưng trở nên đặc biệt khắt khe nhưng bởi sự thật đây là dự án anh rất thích và chắc hẳn các bạn trong đội cũng hiểu đằng sau những câu hỏi tưởng rằng bắt bẻ đó chính là cách anh muốn giúp các bạn hoàn thiện dự án này, đó cũng sẽ là những tình huống mà các bạn sẽ phải đối mặt: "Một khi các bạn hiểu sâu hơn về chính dự án của mình,cơ hội để các bạn thực tế hoá dự án sẽ lớn hơn rất nhiều”, anh Nguyễn Tuấn Quỳnh nhấm mạnh.

Tuy là đội có số điểm thấp nhất trong 3 đội, nhưng điểm nhấn trong dự án "Xây dựng trung tâm Du lịch nông nghiệp đô thị" của đội Đại học Sư phạm Đà Nẵng là đã giúp thay đổi tư duy về nông nghiệp.

Nông nghiệp là một nghề đáng coi trọng, chứ không phải làm nông đồng nghĩa với thất nghiệp. Đây cũng là một hồi chuông mà các bạn muốn gửi gắm đến các nhà làm chính sách địa phương.

Điểm yếu của đội là "Chưa gắn với thực tế và cần 1 quá trình truyền 
thông không chỉ liên quan đến tiền bạc mà còn ở kỹ năng, phương thức truyền thông để làm cho người tiêu dùng hiểu được mục tiêu của công ty mình", giám khảo Vũ Kim Hạnh chia sẻ.

Kêt thúc chương trình, TS Vương Quân Hoàng chia sẻ: "Cái giỏi của các nước phát triển ko phải mang những dự án chi phí cao đặt vào những môi trường dồi dào mà họ linh động, thực hiện những dự án lớn với chi phí phù hợp. Những thành công không phải được quyết định bằng số vốn đầu tư quá lớn. Có những dự án chỉ với số vốn ban đầu là 1-2000 đô nhưng lợi nhuận họ mang lớn hơn rất nhiều". Tin rằng, đây sẽ là bài học đáng nhớ của các đội trên chặng đường khởi nghiệp phía trước.

Hành trình đến các trường đại học, cao đẳng cũng khiến cho các bạn thanh niên các tỉnh thành chờ mong và gây hứng thú nhiều hơn cho các thanh niên nông thôn với diễn đàn"Thanh niên nông thôn nghĩ giàu làm giàu". Sắp tới, diễn đàn sẽ đi qua các tỉnh thành như Tây Ninh (7/11), Khánh Hòa (13/11), Đà Nẵng (20/11), Bắc Giang (4/12), Hải Phòng (11/12).

Từ hậu quả sau vụ bom nguyên tử ở Hiroshima, điều gì đã khiến Nhật Bản chỉ chưa đầy 20 năm sau trở thành siêu cường kinh tế? Điều gì đã khiến Israel từ một sa mạc tưởng như không có sự sống, bị vây bọc bởi gần 350 triệu dân các quốc gia thù nghịch, giờ đây chỉ với 13 triệu dân đã kiểm soát hầu như những lĩnh vực then chốt nhất của thế giới? Điều gì đã giúp Singapore từ một làng chài Malaysia nhỏ bé, nghèo nàn thành đảo quốc văn minh bậc nhất thế giới? Điều gì đã vực Hàn Quốc dậy từ đống tro tàn của cuộc nội chiến đầu thập niên 1950 thành cường quốc top 10? Điều gì đã khiến Dubai từ hoang mạc trở thành trung tâm hội tụ sức mạnh tài chính, công nghệ toàn cầu?... Tất sẽ được giải mã trong khuôn khổ hội thảo chính trong Ngày hội Sáng tạo vì khát vọng Việt lần 2 - sự kiện quy tụ những đại diện trí thức, tinh hoa, những gương mặt Sáng tạo vì Khát vọng Việt - những con người đang ngày đêm miệt mài sáng tạo trong các lĩnh vực chuyên môn, đóng góp trí não, tầm sức, truyền đi ngọn lửa khát vọng, tạo cảm hứng cho thanh niên Việt Nam, khơi dậy khát khao đua tranh với thế giới, dấn thân và sáng tạo vì một nước Việt hùng mạnh, những người đã đồng hành suốt thời gian qua với Hành trình vì Khát vọng Việt, những thanh niên-sinh viên ưu tú trong cả nước và đặc biệt là sự xuất hiện của các học giả quốc tế tới từ Nhật Bản, Đức, Thuỵ Sĩ, Hoa Kỳ, Dubai,... diễn ra từ 7.00-22.00 ngày 23/11/2013 tại Dinh Thống Nhất, TP HCM. Ban tổ chức trân trọng kính mời quý vị, các độc giả, tổ chức,... quan tâm tới chương trình nhận thư mời, vé tham gia tại hệ thống các quán cà phê Trung Nguyên hoặc gửi thư về vikhatvongviet@gmail.com để có thông tin về chương trình. 


\section{Tài liệu tham khảo:}

[1] Vương Quân Hoàng. (2007). Văn minh làm giàu \& nguồn gốc của cải. Nxb Chính trị quốc gia, Hà Nội.

[2] Vuong Quan Hoang, \& Tran Tri Dung. (2009). The cultural dimensions of the Vietnamese private entrepreneurship. The IUP Journal of Entrepreneurship and Development, 6(3), 54-78. 